\title{
Quem somos nós, loucos!? Um ensaio sobre limites e possibilidades da reconstituição histórica de trajetórias de vida de pessoas internas como loucas
}

Yonissa Marmitt Wadi*

Resumo: Este texto apresenta uma reflexão sobre os limites e possibilidades da reconstituição histórica de trajetórias de vida de pessoas comuns, buscando ampliar a compreensão histórica sobre a constituição do sujeito louco. A base da reflexão é a experiência de pesquisa que resultou em minha tese de doutoramento Louca pela vida, a história de Pierina, uma mulher que foi internada como louca, depois de ser indiciada em processo criminal por ter afogado sua filha pequena. A tese resultou de um exercício de interpretação crítica sobre as possibilidades que qualquer texto e qualquer vida apresentam para seu leitor. Exponho assim, as fontes e a problemática da pesquisa tal como ela foi se constituindo, na troca constante entre referências teóricas e as próprias fontes.

Palavras-chave: sujeito louco - trajetórias de vida - pessoas comuns.

* Mestre em História pela UFRGS. Doutora em História pela PUC-SP. Professora da Universidade Estadual do Oeste do Paraná.

Anos 90, Porto Alegre, v. 13, n. 23/24, p.287-319, jan./dez. 2006 
Já faz bastante tempo, pelo menos desde o lançamento do memorável trabalho de Michel Foucault, $A$ bistória da loucura na Idade Clássica (Foucault, 1989) ${ }^{1}$, que os loucos e a loucura deixaram de ser estranhos personagens, alcançando a condição de objetos de análise, tema, problemática de pesquisa, de pelo menos parte da historiografia e de outras das ciências humanas. Alvo de inúmeros olhares, da filosofia à medicina que se construiu como sua legítima enunciadora, passando por escritores e poetas - na sua maioria, considerados malditos -, a loucura e os loucos, mesmo antes de sua descoberta pelo saber histórico, nunca deixaram de ser falados. Porém, raramente esses estranhos personagens puderam dizer de si mesmos e foram ouvidos. Parece anacronismo, pois, e eu não estou esquecendo disto, existem inúmeras terapias que dão a palavra aos ditos loucos, baseando nesta o caminho e a busca da cura. Até mesmo os alienistas dos séculos que se foram deram a palavra aos loucos para que relatassem seus sintomas, para que dissessem dos males que os afligiam. No entanto, esse falar quase sistematicamente foi, e segue sendo ainda hoje, transformado em instrumento médico de confirmação de tal ou qual doença.

Se hoje, pelas mudanças teóricas e práticas em andamento no entendimento da loucura, já podemos sonhar com um estatuto e um lugar diferente para os ditos loucos na nossa sociedade, um espaço no qual ele possa falar e ser ouvido na sua diferença; quando nos voltamos para o passado, isso parece inverossímil. Como ouvir e dar voz a pessoas que, pelas condições nas quais se encontravam, ou seja, loucas e muitas vezes internas num hospício, parecem irremediavelmente condenadas ao silêncio. Surge logo a sentença: "não se pode querer dar voz aos que não tiveram". E nos perguntamos então: quem dentre todos os excluídos foi mais radicalmente silenciado do que os ditos loucos?

Para confirmar essa aparente impossibilidade, contribuem os documentos que guardam a memória da loucura e dos loucos, em sua maioria só visíveis para o presente, nos registros das 
instituições que os enclausuraram. São documentos que emanam dos diversos centros de poder que de formas diversas silenciaram os ditos loucos - especialmente documentos médicos -, e nestes, só os vemos de relance, perdidos em meio às articulações dos saberes. Mas abdicar de dar voz a quem não teve, não implica abdicar de escutar o silêncio. Se aqueles que foram capturados pelo saber (ou saberes) não tiveram voz (pela ausência de direitos, pela completa destituição), os gestos dessa captura falam e falam muito.

Uma série de trabalhos já nos mostrou a possibilidade de

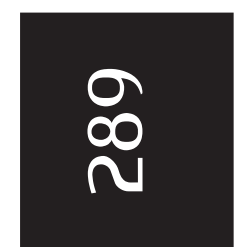
desconstruir gestos monumentalizados em documentos, tornando possível fazer a arqueologia de silêncios vários. Sinais telegráficos, pequenos vestígios, uma série de nadas perdidos em uma variedade de documentos têm possibilitado que uma gama de pesquisadores chegue mais perto de ouvir o silêncio de muitas vidas que por ocuparem as margens da sociedade - foram também deixadas à margem da História disciplina. Dentre esses estão os ditos loucos. A maioria ainda segue ouvindo os saberes - audição fundamental é certo -, porém muitos já se debruçam sobre esse aparente inverossímil.

Deparar-se com documentos que nada dizem sobre a vida desses marginais (Farge, 1993) parece ser o primeiro - mas não o único - obstáculo para aqueles que pretendem trazer vidas anônimas ao cenário da história como contributo à sua compreensão. No entanto, toda regra tem exceção. Partindo de uma exceção que, não milagrosamente, mas pelo próprio exercício do poder médico, faz chegar às mãos dos historiadores - como chegaram às mãos desta historiadora - vestígios da vida dos "homens infames" (Foucault, 1992) ${ }^{2}$, quero introduzir a discussão em torno das possibilidades e limites da reconstrução histórica de trajetórias de vida de sujeitos, ora ruidosos, ora silenciosos e quase sempre silenciados, que são os chamados loucos. A discussão está alicerçada na experiência de pesquisa que resultou em minha tese de doutoramento (Wadi, 2002b). Com o objetivo de cimentar a 
possibilidade - contra as descrenças já bem conhecidas dos historiadores quanto ao uso de certas fontes - de tal reconstituição, apresento a problemática conforme ela foi se constituindo, na troca constante entre os referenciais teóricos e as próprias fontes.

\section{A descoberta das fontes}

No decorrer de meu mestrado na Universidade Federal do Rio Grande do Sul (UFRGS) - no início da década de 1990 pesquisei no Hospital Psiquiátrico São Pedro de Porto Alegre procurando localizar prontuários de pessoas - principalmente de mulheres - que estiveram internas na instituição entre a data de sua inauguração (1884) e os anos quarenta do século XX. Dentro do hospital, encontrei os prontuários espalhados pelos mais inusitados lugares. Muitos exemplares do período 1884-1910 foram encontrados dentro de sacolas de papel ou plástico, amareladas pelo tempo e colocadas no alto de uma prateleira empoeirada na sala de uma funcionária antiga na instituição. Esta, talvez por ser idosa, ou por ser sensível ao desprezo dedicado a tudo o que é considerado velho na nossa sociedade de consumo, guardou por anos a fio aquele punhado de prontuários, pensando que um dia alguém poderia resgatar a memória da também 'velha instituição' e contar a história de tantos olhares escondidos atrás do espelho, quiçá, a sua própria história. Um porão completamente insalubre, chamado 'arquivo morto', guardava o restante dos prontuários psiquiátricos até, aproximadamente, a década de 1950. Amontoados em prateleiras que ameaçavam desabar ou jogados no chão úmido (o porão já sofrera diversas inundações), recolher aqueles documentos referentes ao período que queria analisar, requereu de mim uma dose de sangue frio, um tanto de espírito de aventura, muita paciência, um par de luvas, um par de botas e uma máscara cirúrgica e me deixou como prêmio de consolação uma bela alergia, 
numa sucessão de espirros que se repetiram incessantemente por semanas. Se os espirros me incomodaram, incomodou-me mais encontrar um quadro tão caótico. Ante o desespero de ver milhares de prontuários jogados às traças e outros bichos os quais é melhor não mencionar, eu precisava encontrar aqueles que me interessavam na época. Foi assim, realizando um verdadeiro garimpo, que me deparei com um prontuário psiquiátrico diferente dos demais. Nesse prontuário, além dos papéis comumente encontrados em outros do mesmo período (a década de 1910) - como a papeleta com os dados de identificação e requerimentos e requisições solicitando a internação ou alta -, havia um atestado de peritos que haviam examinado a "paciente" antes da internação, mas também documentos raramente encontrados em prontuários psiquiátricos, ou seja, cartas escritas pela interna.

Acabei por abandonar no mestrado meu intuito inicial de analisar os discursos institucionais - especialmente o da medicina psiquiátrica - no que tange a construção de identidades de gênero, terminando por construir uma "história das lutas pela constituição do saber e do poder psiquiátrico e de seu principal instrumento terapêutico, o hospital de alienados no Rio Grande do Sul" (Wadi, 2002a) $)^{3}$. Na troca de tema, abandonei os prontuários como documentos preferenciais, entre estes, o prontuário com as cartas.

No entanto, a lembrança daquele documento - o prontuário com as cartas - e da história contida nele, nos anos que se seguiram, "ressaltava periodicamente de meus papéis e se fazia presente em minha memória" (Ginzburg, 1987, p.12). Ao iniciar meu doutoramento quase dez anos depois, enfim retomei as já amareladas fichas que elaborara - refazendo e ampliando o levantamento dos prontuários, então já higienizados, organizados e sob guarda do Arquivo Histórico do Rio Grande do Sul -, e pude reencontrar aquela vida e sua história contidas num documento oriundo de uma instituição destinada a silenciar as diferenças. 
Seu nome era Pierina Cechini ${ }^{4}$, branca, casada, filha de imigrantes italianos, nascida e criada em Garibaldi - pequeno município encravado na parte superior da Encosta da Serra -, interior do Rio Grande do Sul, com cerca de 28 anos quando sua história encontrou os marcos institucionais da memória. Foi internada no então denominado Hospício São Pedro, em junho de 1909, depois de ser indiciada em processo criminal por ter afogado sua filha pequena. No tempo em que esteve internada no hospital, ou seja, entre 05 de julho de 1909 e 11 de maio de 1911, Pierina escreveu três cartas e um bilhete que não foram enviados, ficando retidos e sendo anexados ao seu prontuário. Apenas uma das cartas está datada, a dirigida à sua "querida Mãe" em 08 de outubro de 1909. ${ }^{5}$ Sem nenhuma datação - apenas algumas pistas que permitem situálas temporalmente - Pierina escreveu uma carta endereçada a seu cunhado - o oficial de justiça Carlo Peviani -, para ser entregue ao Juiz de Garibaldi: "Caríssimo cunhato o messo el suo nome per Che non sol il nome de Sinhor Juiz ma lui intregue cuesta carta al Juiz. Por favore (...)", é a epígrafe infermeira Bernadeta Da Santa Casa Da Seção 15 Porto Alegre"7; e uma carta dirigida aos "Senhores dottores", possivelmente os médicos legistas da Chefatura de Polícia responsáveis por avaliar se ela 'sofria das faculdades mentais', conforme solicitação da promotoria pública da cidade de Garibaldi.

As cartas de Pierina - anexas ao prontuário - mostraram-se extremamente ricas, intensas em sentimentos e sensações sobre 'como as coisas eram e como podiam ser', sobre os sofrimentos e privações, mas também as alegrias e esperanças que fizeram parte da vida de uma mulher pobre que viveu no início do século XX. Uma mulher que viveu, sobretudo, uma experiência ímpar, uma experiência a que se chamou loucura.

As cartas - contrapostas a outros documentos pertencentes ao prontuário e ao processo criminal - indicaram-me a existência de vários sujeitos (contidos num só) respondendo pelo nome de 
Yonissa Marmitt Wadi

Pierina. Passei então a atentar para o que a fazia um(a) de nós, ao que a aproximava - tendo vivido experiências múltiplas, dentre as quais a da loucura e seu enclausuramento - de tantos homens e mulheres do passado e do presente. Mas também ao que a fazia fundamentalmente diferente de nós, homens e mulheres do século XXI, bem como tão diferente de seus contemporâneos do século passado. Personagem singular foi Pierina, portanto não representativa de uma identidade comum, não redutível a um contexto já delineado, mas cuja singularidade reconstruída analiticamente permite que nos aproximemos de aspectos pouco ou nada conhecidos destes personagens tão estranhos, que são os ditos loucos, os de ontem e os de hoje inclusive. Deles, mas também de nós...

\section{Como resgatar vidas silenciadas}

Em texto de meados da década passada, Peter Pál Pelbart (1995, p.172) afirmou que "o interesse pela loucura entre nós, apesar do refluxo político e dos ventos da acomodação neoliberal, não arrefece[ra]" naqueles anos 1990. Percebia o autor que, num fluxo contrário, "um esforço considerável" estaria sendo feito "a fim de, usando a experiência teórica e prática acumulada, repensar o estatuto e o lugar do louco hoje."

$\mathrm{O}$ autor caracterizou esse hoje como um momento em que a "exclusão dura" foi sendo lentamente "substituída pela branda inclusão", em que "as disciplinas" foram "dando lugar ao controle, em que uma certa neutralidade pseudocientificista de prevenção e gestão" também ganhou terreno, ou seja, um momento em que se estaria adentrando numa nova paisagem no que concerne às "estratégias sociais de enfrentamento com a loucura". Porém, era também naquele preciso momento, dizia o autor, que após um "ruidoso redemoinho", ressurgiram "da poeira os loucos com suas vidas" (Pelbart, 1995, p.172. Grifos do autor.). De dentro de uma 
"nova configuração antropológica em que a loucura deix[ou] de ser uma questão para tornar-se um problema", Pelbart afirmou ter a "impressão de que apenas uma atitude que recusasse suturar as questões de vida dos loucos teria alguma chance de responder a seus problemas de vida" (Pelbart, 1995, p.176. Grifos do autor.).

As palavras de Pelbart ressoaram forte em mim, especialmente aquelas que diziam ser preciso devolver aos loucos as suas vidas. Foi a leitura de seu texto que de certa forma permitiu que eu ousasse finalmente remexer em 'velhos guardados', como o prontuário com as cartas que sugeria a possibilidade ímpar de reconstituir a trajetória de uma pessoa fadada ao silêncio eterno. Uma caminhada longa pelos meandros do saber psiquiátrico - especialmente no que diz respeito à sua conformação regional e conquista de poder e legitimidade -, caminhada atenta ao movimento contemporâneo de sua crítica, configuram a problemática da nova pesquisa que se delineava. A problemática levantada por Pelbart fixou-se como inspiradora dos caminhos a seguir, pois se pode parecer óbvio para alguns - principalmente para aqueles que conhecem, simpatizam e principalmente lutam por "uma sociedade sem manicômios", há cerca de trinta anos no Brasil - que é preciso devolver aos chamados loucos as suas vidas, pouco se sabe do como fazer isso. A tese nasceu assim com a proposição de ajudar a chegar a esse como. Este não se mostrava como um caminho muito simples de ser seguido pois, como afirmou Pelbart:

(...) a micropolítica da existência que agora se impõe, [no] trabalho com a loucura, não pode reduzir-se às tecnologias subjetivas cujo arsenal aumenta a cada dia, em detrimento dos espaços de subjetivação. Todo o desafio consistiria em cultivar a disponibilidade para as dimensões múltiplas que os processos psicóticos mobilizam, atentando para suas matérias e signos, elementos díspares, lógica incomum, atos, cenas, falas, temporalidades, sintomas, etc. Essa produção 
Yonissa Marmitt Wadi

diferenciada, que pede para expressar-se, ser cuidada, desdobrar-se, transformar-se, só tem alguma chance de emergir em sua positividade num espaço (institucional ou não) desimpedido. Ora, atualmente é a cartografia desses processos singulares e desses espaços singulares que é preciso revisitar (...). Seria preciso afinar e enriquecer constantemente estas cartografias, se não quisermos que o desconfinamento sumário dos loucos implique apenas a progressão das tecnologias de normatização subjetiva, ou ainda, o que seria uma outra figura de sua supressão, o mero abandono sob pretexto de reinserção social. (Pelbart, 1995, p.176. Grifos do autor).

O alerta de Pelbart sobre a necessidade de se fazer cartografias de processos e espaços singulares hoje - como uma das formas de contribuir para que os loucos tenham de volta suas vidas -, configurou-se para mim como uma abordagem privilegiada para a recuperação de processos históricos que contribuíssem para pensar esse hoje. Nesse sentido, a reconstrução de experiências outras que tragam à tona as questões de vida, pode somar-se aos esforços contemporâneos no sentido de responder aos problemas de vida dos chamados loucos.

Como alguns, dentre aqueles que lutam pelo fim dos manicômios, perceberam que não basta libertar os loucos para que eles sejam compreendidos e aceitos sem serem 'amarrados' a novas e mais sutis formas de aprisionamento; também a pesquisa no terreno da reconstrução histórica deve buscar não repetir as formas já conhecidas (ainda que meritórias) que deram visibilidade aos mundos dos esquecidos e dos marginalizados, dentre estes os chamados loucos. Correm-se inúmeros riscos com uma proposição dessas, assim é preciso lembrar primeiramente e sempre, que não se pode nem mistificar nem idealizar a loucura, mas que também não é possível deixar de levar em conta o sofrimento concreto dos loucos. Em segundo lugar, é preciso libertar o pensamento - pois 
"enquanto a cidade trancafiava os desarrazoados, o pensamento racional trancafiava a desrazão" (Pelbart, 1990, p.135) -, dar espaço para que ele desarrazoe e para que então se possa "pensar diferentemente do que se pensa" (Foucault, 1990, p.13).?

A documentação encontrada abriu um caminho possível para reconstruir a trajetória de vida de Pierina e esta, no processo de sua reconstituição, tornou-se a possibilidade de mobilizar o que se encontra em 'jogo' quando se trata de destinar um lugar a certas pessoas diferentes. A história de Pierina surgiu então como uma forma de dar 'cara / rosto' a quem na maior parte das vezes tem apenas um nome, um número, às vezes uma foto ou uma digital impressos em uma papeleta médica de um prontuário perdido no meio de um imenso arquivo; dar 'cara / rosto' para quem não passa de um caso clínico, um paciente da síndrome tal ou qual, em estatísticas, relatórios ou às vezes nem mesmo isso, pois sua pista sumiu em meio a incêndios, inundações, doações ou simplesmente descaso com os arquivos de sua memória nas instituições de seu enclausuramento.

Através da trajetória de Pierina foi possível encontrar nos ditos loucos não só estranhamento, mas pessoas que têm histórias, pessoas que têm vidas que, se atingidas pelo sofrimento, pela perturbação, pela loucura ou desrazão, não podem, em nome de uma dita doença mental, inexoravelmente se perder. Algo dos seus gestos, apesar dos muitos filtros, foi monumentalizado em documentos, que ao serem desconstruídos, tornam possível fazer a arqueologia de silêncios vários. Para os que aqui estão, para os que virão perdidos numa rede de sofrimento (ou não), é possível, por uma postura mais ética, mais comprometida, mais engajada e mais disponível, ouvir. Ouvir e buscar compreender as diferenças, não transformando os ditos loucos em quadros, não apenas classificando-os e agrupando-os - a partir de suas queixas, de sintomas expostos ou de sinais percebidos - pelos números de um código de doenças homogeneizador. A trajetória de vida de Pierina 
Yonissa Marmitt Wadi

reconstruída por uma escuta atenta das vozes do passado pretendeu soar como um impulso para que se ouvissem também essas vozes no presente.

\section{A historicidade da loucura}

O crime praticado por Pierina, assim como uma série de atitudes, comportamentos e acontecimentos anteriores que, segundo sua própria narrativa, levaram ao ato extremo, foram interpretados - inclusive por ela mesma - invariavelmente como fruto da loucura que a tomara. Em leituras de senso comum ou naquelas dita científicas, encontraremos ainda hoje, com certeza e em grande quantidade, a atribuição imediata do rótulo louca (em vez de criminosa) para uma mãe que mata seu filho.

Não nos enganemos, no entanto, pois tais leituras, que atribuem rótulos e lugares para as pessoas, não são unificadoras nem unívocas. Critérios diversos presidem tais atribuições, critérios nem sempre claros ou explícitos, amadurecidos ou refletidos ancorados na tradição, mediados por relações de poder, por experiências e costumes, por conceitos e preconceitos, teorias, crenças religiosas ou morais. Critérios moldados e fixados pelas sociedades de acordo com o contexto cultural e o momento histórico que vivem, mas em embate, adequação e transformação constante.

Joana Pedro (1999a) analisando casos de mortes de crianças por suas mães, cometidos por mulheres em Florianópolis entre as décadas de 1870 / 1940, não menciona nenhum caso de internação por loucura dessas mulheres. Todas foram presas e processadas como criminosas. Em outros contextos sociais como a Inglaterra e a França dos séculos XVII/XVIII, ou entre tribos africanas, Laura Gowing (1997) e Germaine Greer (1987) falam de aceitação velada de infanticídios e homicídios cujas vítimas são crianças, bem como da consideração destes como a forma mais branda de morte 
para os pequenos com fome (especialmente as meninas, preteridas quando havia escassez). Contextos históricos diferentes, personagens diferentes, gerando interpretações diferentes de um mesmo acontecimento: a morte dos filhos por suas mães.

As fragilidades reveladas, as singularidades dos modos de ser, os comportamentos peculiares, as vontades e os desejos, as dificuldades de adaptação às regras, normas, instituições, a transgressão, a capacidade de desterritorialização que advêm das experiências vividas pelos sujeitos sociais têm em determinados momentos históricos conformações específicas - e eu estava trabalhando com a passagem do século XIX para o XX, momento de nascimento da psiquiatria no Brasil -, alvo de formas diferentes de saber e de relações de força diferenciadas, os poderes.

Buscar conhecer e interpretar a história de Pierina com todos os seus desdobramentos não previsíveis, a despeito do que diziam os médicos - que viram nela uma perfeita "degenerada inferior", cujos sinais estavam no corpo e nos comportamentos anunciados que a levaram até onde foi (a alienação e o crime) - foi um caminho possível que, para mim, apresentou-se como o mais rico em possibilidades interpretativas e de conhecimento. Seguir a história de vida de Pierina permitiu nuançar as diferenças de circunstâncias e experiências de pessoas homogeneizadas por um modelo interpretativo - o da medicina psiquiátrica - que, legitimado, circunscreveu os limites e as possibilidades de cada um que mergulhou no mundo da loucura. Foi assim que pude, também eu, chegar a discussão atual de como restituir aos loucos as suas vidas.

Uma observação importante que me furtei de fazer até agora, para não perder o fio de linha que alinhava meu pensamento, foi quanto ao que entendo como loucura e sobre quem é o louco. Tanto o conceito quanto o personagem circunscrito por este adquirem em contextos diferentes, também contornos diferenciados, e disso já nos alertou brilhantemente Michel Foucault. Uma distinção conceitual proposta por Peter Pelbart é de onde parto para 
Yonissa Marmitt Wadi

pensar meu objeto: "Por louco entendo esse personagem social discriminado, excluído e recluso. Por loucura, que para facilitar chamarei (...) de desrazão, entendo uma dimensão essencial de nossa cultura: a estranheza, a ameaça, a alteridade radical, tudo aquilo que uma civilização enxerga como o seu limite, o seu contrário, o seu outro, o seu além" (Pelbart, 1990, p.133).

Porém, nem sempre a loucura do louco permanece desrazão. Por um lado, capturada pela psiquiatria, a loucura transforma-se em doença mental e no interior dos manicômios, produtores maciços de identidades (Lancetti, 1990, p. 143), os loucos poucas vezes invocam a desrazão. Por outro, nas brechas do processo de captura psiquiátrica, emergem momentos de disrupção, de desterritorialização, que podem também ser entendidos como momentos de subjetivação.

Apesar dessa compreensão sobre os sentidos da loucura, o forte conteúdo negativo e mesmo pejorativo que cerca a palavra, além "dos pesados reducionismos 'fisicalistas' que cercam essa representação entre nós, por força da instituição médica e de sua inarredável legitimidade" (Duarte, 1998, p.13), fizeram com que eu buscasse outras noções / categorias que pudessem nomear os acontecimentos que foram rememorados por Pierina em suas cartas e por vários dos outros atores envolvidos nessa trama e que levaram-na a ser considerada doente mental. Considerei tais acontecimentos como momentos de condensação de um processo que vinha se desenvolvendo desde o casamento de Pierina em 1905 quiçá desde tempos idos - e optei por nomear aquilo que os médicos consideraram sintomas e sinais de doença mental, com os termos perturbação e sofrimento, em vez de usar os termos médicos, doença, doença mental, alienação ou mesmo loucura. ${ }^{10}$

Segundo Luiz Fernando Dias Duarte (1998), justapor as categorias sofrimento e perturbação, noções de sentido mais abrangentes e utilizadas pelo senso comum para referir-se à doença, tem efeito relativizador frente a reducionismos e preconceitos. 
A categoria sofrimento, que nas línguas latinas apresenta-se como uma alternativa à categoria dor, constitui uma forma de lidar com o adoecimento, pois o "que faz o essencial da 'doença', ou seja, a experiência de uma disrupção das formas e funções regulares da pessoa, implica necessariamente o 'sofrimento, quer se o entenda no sentido 'físico' mais restrito, quer se o entenda no sentido 'moral', [mais] abrangente (...) e que engloba, inclui, o sentido físico". $\mathrm{O}$ autor entende, que de um ponto de vista antropológico,

... a gama dos 'sofrimentos' nomeáveis pela experiência humana é muito mais ampla que a sucessão de idéias pelas quais algumas culturas - e, em particular, a ocidental - os entendem como 'doença', ou seja, ocorrência efetiva de uma disrupção física (...) ou o reconhecimento culturalmente sancionado de uma forma de evento ou situação disruptiva definida (...). As imprecisões e vicissitudes da categoria 'doença mental', criada para abarcar a maior parte das antigas formas da 'loucura' no Ocidente, bem demonstram as dificuldades de se estender a convenção fisicalista da 'doença' para as formas globais do 'sofrimento'. (Duarte, 1998, p.13).

Sendo assim, esse esforço de relativização antropológica dos fenômenos de disrupção conduz ainda à utilização da categoria perturbação, uma herança da antiga tradição médico-filosófica do Ocidente. Para Duarte, colocar as 'doenças' e os 'sofrimentos' dentro do quadro mais abrangente das 'perturbações', permite admitir que muitas situações reconhecidas como 'patológicas', especialmente nas versões mais eruditas ou oficiais da cultura Ocidental podem ser consideradas 'regulares' em outras culturas, deixando mesmo de implicar qualquer 'sofrimento' peculiar". Segundo o autor, é também claro,

... que as 'perturbações' (...) tendem a apresentar-se sob forma 'f́́sico-moral', se não exclusivamente 'moral', lembrando-nos de que esta categorização só faz sentido com base 
Yonissa Marmitt Wadi

na nossa peculiar concepção dualista do humano (...). Mais uma vez, os fenômenos associados ao que se pode chamar de doença mental se impõem à reflexão. Sua relação freqüente com crenças ou explicações 'religiosas', por um lado, ou com manifestações do 'cultivo de si', tais como a criatividade artística ou o consumo de drogas, por outro, demonstram o quanto são cruciais para a vida humana e podem distanciar-se da negatividade do 'patológico'. O certo, porém, é que elas também podem ser eventualmente consideradas como relacionadas ao 'adoecimento' em uma cultura fortemente marcada pela hegemonia das representações fisicalistas da Biomedicina. (Duarte, 1998, p.13).

A adoção da categoria 'perturbações físico-morais' permite romper com a segmentação imposta, por uma cultura individualista, a fenômenos humanos - chamados ora doença mental, ora possessão ou transe, ora distúrbio psíquico, distúrbio psicossocial ou mesmo somatização - e que são pertencentes a uma mesma esfera. Para Duarte, o "qualificativo 'físico-moral' procurava justamente reconstituir o caráter de vínculo ou mediação de que esses fenômenos se cercavam nas relações entre a corporalidade e todas as demais dimensões da vida social, inclusive, e eventualmente, a espiritual ou transcendental". (Duarte, 1998, p.22).

\section{Experiência e loucura}

Quando retomei o tema 'mulheres e loucura' no decurso do doutorado, formulei inicialmente a problemática de pesquisa em torno de reconstruir e compreender experiências vividas por diferentes mulheres tidas como loucas e internas no então Hospício São Pedro de Porto Alegre / RS, entre as décadas finais do século $\mathrm{XIX}$ e as primeiras quatro décadas do século XX. Entretanto, logo emergiram perguntas e dúvidas que eu não sabia muito bem como resolver.

Anos 90, Porto Alegre, v. 13, n. 23/24, p.287-319, jan./dez. 2006 
Como reconstruir e compreender experiências de forma densa? Como ultrapassar uma forma que se poderia chamar panorâmica, ou seja, aquela que mostraria quem eram as mulheres que estiveram internas (idade, estado civil, cor, profissão, naturalidade, procedência, diagnóstico, etc.)? É claro que esses elementos ajudariam a recompor os sujeitos, contribuiriam com indícios fundamentais para se chegar às questões de vida, mas ainda não esclareceriam os problemas de vida. Como ir além da desconstrução do discurso da psiquiatria ou de outros envolvidos na captura da loucura? Os aportes teóricos, os empreendimentos práticos no gerenciamento do espaço institucional, as diferentes configurações do saber no trato com os internos, os embates inter e intra-saberes, as estruturações dos discursos na configuração dos sujeitos, constituía todo um panorama que seria preciso traçar, mas que por si só não respondia ainda à pergunta inicial.

Depois de idas e vindas, o reencontro com os documentos de Pierina (tanto o prontuário com as cartas, como o processocrime no qual foi indiciada) indicaram-me o caminho a seguir. Um olhar mais vibrátil lançado a documentos já tantas vezes manuseados permitiu deixar-me arrastar por uma linha que, se não era exatamente outra, também não era mais a mesma. Longe da máxima "positivista" de que os documentos falam por si mesmos - mas deixando-me tocar pela força do que via - encontrei enfim um caminho. (Rolnik, 1997).

O olhar tocado pelas narrativas de Pierina lançou-me subitamente num redemoinho. Naqueles documentos visualizei uma vida condensada, visualizei a possibilidade de recuperar tantas coisas, de passear por tantos lugares. Pareceu-me, especialmente, que havia a possibilidade de reconstruir os caminhos que levaram alguém a viver uma experiência que foi chamada de loucura; de compreender que experiência foi essa para quem a viveu; o que significou para os 'outros' (a família, o grupo social, os saberes...); como esses 'outros' construíram tal experiência; como esta pôde ser 
'capturada' e 'aprisionada'; que sujeito surgiu no aprisionamento; como foi o contato, a troca com seus 'iguais' - demais pessoas tidas como loucas -; como foi o encontro com os operadores dos saberes; que possibilidades havia para aquela mulher, naquele tempo e naquele lugar onde viveu? Quais as linhas de fuga possíveis?

Mas o que era denso pode se descondensar permitindo que se veja além. Como quando por detrás da chuva, já começamos a enxergar o arco-íris. O que surgiu então a partir daí? No descondensar surgiu uma estrutura de tese possível, na qual segui querendo reconstruir e entender como certas experiências vividas por sujeitos sociais - mais especificamente mulheres - foram entendidas, lidas e aprisionadas como loucura, como se transformaram em doença-mental. Mas enfim, com maior clareza esboçaram-se as perguntas que se desdobrando da pergunta inicial podiam dar densidade à vida de mulheres chamadas de loucas. Assim: Experiências vividas indicam a busca de uma singularidade por quem as viveu? Os momentos / atos que foram lidos / interpretados (pelos saberes, pelas famílias, pelas comunidades, ou mesmo pelas pessoas que os vivenciaram) como loucura, seriam momentos / atos constituintes de um processo de subjetivação? A loucura / desrazão pode ser lida como parte do processo de construção da subjetividade? Seriam linhas de fuga em busca de "um possível para não sufocar?" (Deleuze, 1998, p. 131).

Tomando-se o caso de Pierina - caso singular, caso-exemplo (não exemplar) -, considerando-se suas atitudes, comportamentos, o ato extremo do assassinato da filha, que experiência foi essa? Seus atos foram atos desarrazoados, loucos no sentido de força de disrupção, de transgressão, de desterritorialização? (Pelbart, 1990, p. 132-3). Ela atingiu essa experiência vivendo um processo de busca da subjetivação? Pode-se ler sua vida e seus atos assim? Que componentes de seus atos levaram-nos a serem lidos pelos operadores do saber e por outros (inclusive ela mesma) como loucura, devendo e podendo assim ser aprisionada no 
hospício? Por que ela não foi somente considerada uma criminosa quando matou a filha? Como os operadores do direito e os da psiquiatria (nascente) compuseram essa trama? Que embates houve entre os saberes em torno desse acontecimento (pois embates entre medicina e direito em torno de definir o espaço de "loucoscriminosos" eram comuns neste momento histórico)? Como Pierina viveu o aprisionamento? Que encontros aconteceram? Que experiências se cruzaram? Que sujeito nasceu aí?

Percebi que trabalhar em cima da história de Pierina, me permitiria trazer toda a problemática inicial no cruzamento das diversas fontes, dos diversos discursos - quem eram as mulheres internas, quais as motivações, como os saberes operavam, etc. -, mas enfim, alargar minha discussão no sentido de pensar 'os possíveis de hoje' que afinal foi sempre o que me motivou. Recontando esse passado, não faria mais do que me interrogar sobre este presente afinal tantos seguem sendo internados mesmo nesta época de desospitalização, tantos seguem sendo mal-compreendidos por uma psiquiatria em plena época de repensar de sua teoria-prática. Mesmo assim, as questões de gênero não se diluíram, pois as estatísticas, as notícias, os acontecimentos ainda nos dão conta - além de outras coisas - que as mulheres ocupam a maioria dos leitos psiquiátricos, são também o maior contingente na busca de ajuda dos diversos campos "psi". E as assertivas sobre a "criação de novos modos de existência", a "invenção de novas possibilidades de vida" ou sobre "quais são os nossos processos de subjetivação" não são questões que ao serem proferidas nos permitem sonhar com um “pouco de possível” para não sufocar? (Deleuze, 1998, p. 131).

\section{Uma questão de gênero}

Uma segunda observação importante que também me furtei de fazer até o momento - por exigências do processo (muito 
pessoal) de escrita -, é que a tese foi pensada como uma história das mulheres e das relações de gênero. ${ }^{11}$ Ao reconstruir a história de Pierina, tentava abrir caminho para a visibilidade e para a compreensão de histórias de outras tantas mulheres perdidas atrás do espelho ${ }^{12}$, perdidas no labirinto da internação em instituições dedicadas à 'cura' de uma suposta doença mental, lugares estes onde os atributos de gênero são 'solicitados' o tempo todo.

Todas as mulheres que um dia ocuparam os leitos do hospital psiquiátrico eram pessoas constituídas a partir de diferentes identificações, que se reconheceram na relação com 'outros' (em redes de parentesco, vizinhança, papéis sociais, etc.) e que não podem ser reduzidas a qualquer coletividade, exatamente o que o discurso médico tenta fazer. $\mathrm{Na}$ abordagem da tese, as mulheres são vistas como múltiplas e diferentes, com práticas, necessidades e vivências marcadas por distintos atributos (de gênero, classe, raça, etnia, geração, idade, religião...) e que em sua experiência cotidiana, no processo de construção de subjetividades, de alguma forma configuraram-se como "outros" da razão. Ao reivindicarem espaços, ao não se adaptarem, ao transgredirem e/ou romperem com padrões e regras de normalidade (como a da mãe amorosa, de esposa zelosa, etc.), ao entrarem em choque com outros poderes (micro-poderes certamente), abriram espaços para novas relações de força se constituírem, tornando-se internas do hospital psiquiátrico e 'pacientes' dos alienistas.

Formadas na limiaridade de posições subjetivas contraditórias ou por fluidas, nomádicas e migratórias subjetividades (Hita, 1998), e vivendo múltiplas temporalidades, muitas mulheres ao enredarem-se em diferentes teias discursivas e ao serem marcadas por acontecimentos diversos, certamente não suportaram os paradoxos de seu viver e tornaram-se alvo da captura psiquiátrica. São essas situações paradoxais, as vivências, os acontecimentos, enfim, as experiências que construíram certas mulheres como sujeitos passíveis de institucionalização e que configuraram uma 
longa rede de relações, que tentei recuperar através da história de Pierina.

Inúmeros trabalhos têm trazido à tona experiências múltiplas de sujeitos sociais diversos, documentando mundos escondidos e esquecidos pela densa camada de poderes e saberes (vitoriosos / hegemônicos / onipotentes...) sobrepostos. Muitos têm sido dedicados às mulheres, desmontando (pelo menos no nível do conhecimento intelectual) aparatos milenares sobre seus pendores, sua natureza, seus lugares, suas aptidões e por aí afora. As mudanças concretas, no entanto, ainda estão distantes de atingir a maioria das mulheres permitindo-lhes serem reconhecidas com suas potencialidades, limites, desejos, subjetividades. Ou seja, em sua diversidade, que não é mais nem menos, que não pode ser julgada por critérios de valor falocêntrico ${ }^{13}$. Sendo assim, a tese soma-se a um vasto leque de trabalhos que têm contribuído para o desvelamento dos múltiplos processos sociais que atuam no sentido de criar sistemas de dominação e exclusão. Porém, quis-se ir além de tornar visível a experiência das mulheres tidas como loucas, mostrando como suas experiências foram construídas e como construíram novos sujeitos, no caso, sujeitos da loucura.

Parafraseando Joan Scott $(1998)^{14}$, documentar o mundo escondido da loucura, tentando dar vOz aos silenciados e assim, mostrando o impacto do silêncio e da repressão nas vidas que foram afetadas, trazendo à luz a história de como foram suprimidas e exploradas, constitui um problema de extrema importância. Porém, tornar visível a experiência de mulheres consideradas loucas não garante visibilidade ao funcionamento dos processos sociais que as constituem em sujeitos da loucura e não mostra necessariamente sua historicidade; ao invés disso, pode reproduzir seus termos. Sabemos que mulheres loucas existiram (e seguem existindo), conhecemos seu sofrimento, suas privações, sua opressão (no sistema asilar ou fora dele); mas não sabemos que / quais / como as experiências, os discursos, os acontecimentos construíram 
essas mulheres, marcaram suas vidas, confluíram em torno delas para que em determinados momentos ocupassem o lugar de sujeitos da loucura. Sabemos que a experiência delas oferece uma crítica de práticas normativas e expõe a existência de mecanismos repressivos, mas não desnuda a dimensão da crítica ou a lógica e o funcionamento interno desses mecanismos. Sabemos que a diferença existe, mas não a entendemos como constituída em relação mútua.

Assim, para ir além, é preciso analisar, interpretar e buscar compreender em maior amplitude os processos históricos que, através de discursos, posicionam os sujeitos e apresentam suas experiências. Mulheres consideradas loucas não são simplesmente indivíduos que têm experiência, mas sim, sujeitos que são constituídos na - e pela - experiência.

Experiência nesta definição torna-se, então, não a origem de nossa explanação, não a evidência legitimadora (porque vista ou sentida) que fundamenta o que é conhecido, mas sim o que procuramos explicar, sobre o que o conhecimento é apresentado. Pensar sobre a experiência desse modo é historicizá-la, bem como historicizar as identidades que ela produz. (Scott, 1998, p.304).

É exatamente nesse sentido que a tese foi fortemente marcada pela reconstrução da biografia da Pierina.

Da mesma forma, tornava-se necessário olhar para outros lados, especificamente para o lado do saber-poder que em sua ação direta (no hospício) ou de forma indireta (na disseminação social de certos preceitos) capturou Pierina e tantas outras, e que - sintetizando o significado de sua abrangência - foi o responsável por nos apresentar essas experiências a partir dos documentos que produziu.

Era preciso assim, entender como a psiquiatria construiu o sujeito louco. Uma literatura extensa já demonstrou que desde o 
início de sua gestação como saber, passando pelos momentos de luta por afirmação, até a conquista prática e formal dos aparelhos institucionais de guarda dos loucos, do reconhecimento jurídico e social como o verdadeiro saber/poder sobre a loucura, a psiquiatria construiu e reconstruiu os sujeitos desta. Essa construção levou o saber à realização de dois movimentos que pretenderam soar como um só e que podem ser claramente situados temporalmente: 1) a busca de uma identidade una para a loucura anulando as múltiplas subjetividades dos sujeitos, reconstruindo-os como loucos; 2) a constituição desta identidade marcada por diferentes atributos de gênero e, imbricados nestes, atributos de classe, raça / etnia, geração, etc.

A identidade objetivada construída pela psiquiatria para a loucura como única, acredito ser em primeiro lugar - mas não em único -, bipartida. Atributos de gênero têm se constituído como uma primeira maneira de significar a construção do sujeito louco pela psiquiatria, ou seja, estão no cerne da construção dessas relações de poder. Algumas autoras, como Cunha (1989), Garcia (1995) e Showalter (1985), já indicaram em suas análises que critérios de gênero aparecem claramente como uma primeira maneira de dar significado às relações de poder em construção no interior do campo da psiquiatrização do diferente (dito louco). Esses critérios, ainda que muitas vezes sejam utilizados isoladamente, em inúmeras outras, aparecem conjugados aos atributos de classe, raça / etnia, geração ou idade, por exemplo. Para essas autoras é evidente que uma concepção subordinada da natureza feminina está implícita na definição de papéis sexuais e sociais em que se igualam todas as mulheres, seja na escala do internamento como em qualquer situação social, onde "elas serão sempre inferiorizadas quando confrontadas aos homens com os quais convivem". (Cunha, 1989, p.126).

Se em sua constituição, a psiquiatria delimitou teoricamente os sujeitos da loucura como unos, objetivando-os e tornando-os 
Yonissa Marmitt Wadi

passíveis de serem reconstruídos pelo seu saber; na prática clínica, nas diversas instâncias de intervenção, considerou os sujeitos já de início bipartidos pelas referências de gênero, estabelecendo suas práticas sobre híbridos de natureza e cultura: o corpo, o útero, a descendência, a hereditariedade, as paixões sociais, o progresso da civilização foram elementos mesclados na construção dos sujeitos loucos da psiquiatria. Nesse sentido, foi preciso recuperar a rede longa (Latour, 1994) ${ }^{15}$ que envolveu essa construção e mostrar que a psiquiatria, no processo de sua própria constituição como saber e na sua tentativa de conformar o sujeito louco com uma identidade una e em oposição binária ao não-louco, na realidade construiu um sujeito louco híbrido (de natureza e cultura) marcado por acontecimentos (o gênero, a raça, a etnia, a geração, a idade, a religião...) que atravessaram os corpos destes e dos próprios sujeitos do saber médico. ${ }^{16}$

\section{Subjetividade e loucura}

Para que todos esses supostos adquirissem maior compreensão, era preciso recompor e analisar os momentos e espaços de encontro. No espaço do hospício em construção ${ }^{17}$, o cruzamento do saber psiquiátrico - com seu sujeito louco ideal - e a multiplicidade de sujeitos mulheres, dentre elas Pierina - mulheres estas formadas por uma diversidade de experiências -, configurou-se como o espaço da construção de novos sujeitos, de novas subjetividades. Num espaço reinventado constantemente - o do Hospício São Pedro -, as práticas discursivas dos operadores da psiquiatria, no embate entre si, com outros saberes e com os ditos loucos, forjaram novas experiências que construíram pessoas como sujeitos da loucura, duplamente como doença-mental ou como espaço de desrazão. Na linha das reflexões de Foucault, visualiza-se claramente que o confronto entre mulheres tidas como 
loucas e os outros que as definiram como tal (família, autoridades públicas, sociedade, psiquiatras...) foi uma luta. Estabeleceram-se relações de poder desiguais que envolveram dominação, degradação de um dos termos da relação, ou seja, do(a) louco(a). Não foram estas, no entanto, relações absolutizadas, pois inúmeras vezes desestabilizaram-se ou romperam-se pela resistência sempre presente em relações de poder ou por linhas de fuga, que foram às vezes suicidas, às vezes criativas...

Com essa configuração da problemática, uma hipótese central (ou intuição?) pôde ser esboçada, ou seja, a idéia de que no processo de construção de subjetividades se constroem também experiências de enlouquecimento. Essas experiências traduzem-se em dor, sofrimento, constrangimento, separação, afastamento, não conformidade com o mundo no qual se vive. Mas também, significam disrupção, transgressão, explosão artística, encantamento... Essas experiências, que surgem como momentos de subjetivação, são forjadas por outras experiências vividas - portanto, urge recuperá-las, situando as mulheres em seu mundo, seus lugares, seu tempo... - e por discursos diversos, que tornados acontecimentos, marcaram as vidas das pessoas.

Mas o que é a subjetivação? Deleuze (1998b) remete a explicação para Foucault, para quem subjetivação é transpor a linha de força, ultrapassar o saber-poder, curvar a força.

(...) fazer com que ela mesma se afete em vez de afetar outras forças: uma dobra, segundo Foucault, uma relação da força consigo. Trata-se de 'duplicar' a relação de forças, de uma relação consigo que nos permita resistir, furtar-nos, fazer a vida ou a morte voltarem-se contra o poder. (...) processos de subjetivação são inteiramente variáveis, conforme as épocas, e se fazem segundo regras muito diferentes. Eles são tanto mais variáveis já que a todo momento o poder não para de recuperá-los e de submetê-los às relações de força, a menos que renasçam inventando novos 
Yonissa Marmitt Wadi

modos, indefinidamente (...). Um processo de subjetivação, isto é, uma produção de modo de existência (...), é um modo intensivo e não um sujeito pessoal. É uma dimensão específica sem a qual não se poderia ultrapassar o saber nem resistir ao poder. (Deleuze, 1998b, p.123).

Chocar-se contra o poder é o destino do homem moderno (o homem infame), pois é esse poder que nos faz ver e falar, diz Foucault (1992). Entretanto, sempre existem pontos de resistência ao poder (a resistência é o duplo do poder), mas onde eles estão? Como se transpõe essa linha da força? Talvez entrando noutra linha, na linha do Fora, a linha que está além do saber e das relações de poder. "Creio que cavalgamos tais linhas cada vez que pensamos com suficiente vertigem ou que vivemos com bastante força", diz Deleuze (1998a, p.137).

A linha do Fora é nosso duplo, com toda alteridade do duplo. (...) essa linha é mortal, violenta demais e demasiado rápida, arrastando-nos para uma atmosfera irrespirável. Ela destrói todo pensamento (...). Ela não é mais que delírio ou loucura (...). Seria preciso ao mesmo tempo transpor a linha e torná-la vivível, praticável e pensável. Fazer dela tanto quanto possível, e pelo tempo que for possível, uma arte de viver. Como se salvar, como se conservar enquanto se enfrenta a linha? É então que aparece um tema freqüente em Foucault: é preciso conseguir dobrar a linha, para constituir uma zona vivível onde seja possível alojar-se, enfrentar, apoiar-se, respirar - em suma, pensar. Curvar a linha para conseguir viver sobre ela, com ela: questão de vida ou morte. A linha mesmo não pára de se desdobrar a velocidades loucas, e nós, nós tentamos dobrar a linha, para constituir 'os seres lentos que somos', atingir o 'olho do ciclone, como diz Michaux: as duas coisas ao mesmo tempo. (...) Dobras e desdobras, é isto (...) a operação própria a uma arte de viver (subjetivação). (Deleuze, 1998a, p.138-9).

Anos 90, Porto Alegre, v. 13, n. 23/24, p.287-319, jan./dez. 2006 
A vida dos homens e mulheres, entendido o pensamento de Foucault, é um movimento constante em meio a saberes / poderes e tentativas de dobrar a linha do Fora, subjetivação. Segundo Deleuze, para Foucault a subjetividade não tem lugar no interior do saber ou do poder e não é, de modo algum, uma formação do primeiro ou uma função do segundo: "Não se deve acreditar que a subjetivação, isto é, a operação que consiste em dobrar a linha do fora, seja simplesmente uma maneira de se proteger, de se abrigar. Ao contrário, é a única maneira de enfrentar a linha e de cavalgála: talvez se vá à morte, ao suicídio (...).” (Deleuze, 1998a, p.141).

Pode-se chegar à loucura, ao desarrazoamento? O pensamento desarrazoado, a loucura, pode ser entendida como uma experiência de desmoronamento que sucede a uma tentativa de curvar sobre si a força, de colocá-la sobre si, de fazê-la afetar a si mesma? E quando a loucura - que eu entendo como potencial de desterritorialização ${ }^{18}$ - é marcada com atos como um crime, onde estamos? ${ }^{19}$ Para os operadores dos saberes o embate também foi árduo, ainda que - naquele tempo a que me reporto - certamente suas dúvidas os conduzissem a um entendimento diferente, a questões diversas das que formulei: para muitos daqueles operadores a pergunta girava em torno de saber se atos como o de Pierina eram atos de um criminoso comum (e, portanto, deveriam ser punidos seguidas as regras do Direito Legal) ou de um doente-mental (o louco psiquiatrizado) e deveriam ser 'tratados pela psiquiatria, a recém-nascida 'ciência'.

\section{Uma história possível}

Buscando dar materialidade a essa aventura do pensamento, a tese foi dividida em cinco partes: um prólogo, três capítulos e um epílogo. No prólogo, intitulado O crime de Pierina, narrei a seqüência de acontecimentos imediatamente anteriores e posteriores 
à morte da filha pela mãe. Considerei essa narrativa como a abertura mais adequada à tese, pois foi a partir desse acontecimento que Pierina, personagem fadado a ser invísivel, tornou-se vísivel para a História disciplina e tornou possível escrever a tese. Seu ato de matar a própria filha levou-a ao encontro dos saberes institucionalizados. Sua história encontrou, assim, os marcos institucionais da memória, aqueles que a trouxeram de tão longe para tão perto de nós.

No capítulo 1 - chamado Caminhos - procurei mostrar por

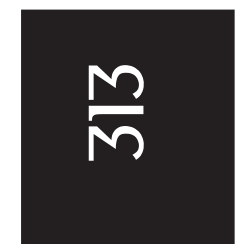
quais caminhos seguiu Pierina, dentre os possíveis na época em que viveu. Fiz isso através da reconstrução do contexto cultural, social e familiar, e de algumas das experiências que a constituíram como diferentes sujeitos em diversos momentos de sua trajetória: o trabalho, o namoro, o casamento, a maternidade, as relações familiares e as relações de sociabilidade. O segundo capítulo, intitulado Loucuras, reconstituiu as interpretações, representações e práticas dos diferentes sujeitos sociais relativas ao processo de perturbação - dita loucura - de Pierina. Segui os passos de Pierina e de seus familiares, do momento em que pela primeira vez - assaltada por um pensamento lúgubre - ela teve vontade de morrer e 'percebeu-se então louca', até o momento em que - passados nove meses -, um segundo pensamento funesto incitou-a a matar sua filha. Busquei fundamentalmente refletir sobre como as pessoas comuns, em situações históricas determinadas, lidam com experiências de sofrimento, saúde e doença, loucura e lucidez; que sentidos elas atribuem a essas experiências, bem como que soluções buscam para os problemas.

No capítulo 3, Labirintos, reconstituí não só os encontros de Pierina com os saberes institucionalizados e seus poderes, mas também os encontros com outras pessoas que, como ela, mergulhadas num processo de sofrimento, tornaram-se internas do hospital psiquiátrico e pacientes dos alienistas. Descrevendo a montagem do processo-crime e a passagem de Pierina pelo Hospício 
São Pedro, apresentei os saberes e a teia discursiva que construíram na interpretação da chamada 'loucura de Pierina'. Narrando a trajetória de Pierina dentro do hospício - misturada a outras histórias de homens e mulheres seus contemporâneos -, tentei mostrar as dissensões entre a teoria e a prática dos primeiros psiquiatras, bem como as diferentes experiências das mulheres internas, forjadas em meio ao labirinto de idéias, vivências e práticas, marcadas por atributos de gênero, classe, raça / etnia, geração.

A tese se encerra com o epílogo Finitudes, que traz à reflexão uma idéia importante: a de que os encontros dos saberes com as vidas, os caminhos nos labirintos e as loucuras..., levam a um fim, são transitórios e contingentes, mesmo que se repitam incessantemente. O 'fim' na verdade são diversos fins, possibilitados pela resistência sempre presente nas relações de poder, pela acomodação - que pode indicar também resistência - ou por linhas de fuga que podem ser suicidas ou criativas. Conto aqui o 'destino' de Pierina que, passados dois anos de internação no Hospício São Pedro, retorna à sua cidade natal para apresentar-se ao Chefe de Polícia.

Logicamente, esse destino é delimitado pelos meandros da tese que limita a vida dos sujeitos ao espaço da narrativa historiográfica. Atento, pensando no que aconteceu com Pierina a partir de então, para o que disseram Vianna (1988) e Blanchot (1955, apud Alberti, 2000) sobre o curso do mundo - ou o curso da vida? - como lugar do trabalho, da ação, do tempo e de todas as finitudes possíveis. Se o "mundo está entregue a infinitos possíveis", então "qualquer escolha é um empobrecimento" (Vianna, 1988, p.62) e as escolhas 'possíveis' de Pierina certamente o foram, fazendo com que o historiador e seus leitores, sedentos de um desfecho digno de manchete jornalística, tenham de contentar-se com o pouco glamour das 'vidas infames' dos sujeitos comuns, que se alçadas um dia à glória de fato histórico - pela escolha pouco convencional de um sujeito escritor - retornam à sua 


\section{Yonissa Marmitt Wadi}

inarredável simplicidade, ofuscamento, insignificância, tão logo cesse a escrita. Pode esta, a escrita, ser interrompida exatamente por esse curso do mundo - marcado pela cotidianidade - que, tão diferente do espaço literário - "incessante, interminável, infinito, atemporal” (Blanchot, 1955, apud Alberti, 2000, p.207) - obriga a mão a 'largar o lápis'.

Recebido em 21/06/2006.

Aprovado em 02/08/2006.

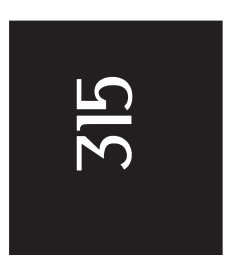

Who are we, crazy people?! An essay on the limits and possibilities in historical reconstitution of life trajectories of people confined as insane

Abstract: This text shows a reflection about the limits and possibilities of the historical reconstitution of trajectories of life of ordinary people, it is searching to extend the historical understanding about the constitution of mad subject. The base of the reflection is the research experience that resulted in my thesis Louca pela vida, a história de Pierina, a woman that was interned as insane person, after being accused in criminal proceeding due to having drowned her little daughter. The thesis resulted of an exercise of critical interpretation about the possibilities that any text and any life show for its reader. I explain thus, the sources and the research problematic one as it was constituted, in the constant exchange between the theoretical references and the proper sources.

Key-words: mad subject - trajectories of life - ordinary people.

\section{Notas}

${ }^{1}$ A primeira edição francesa do livro de Foucault foi publicada em 1961, a primeira em língua inglesa em 1965 e a primeira em português em 1978.

${ }^{2} \mathrm{O}$ homem infame, neste texto de Foucault, não diz respeito àquele que é baixo, torpe, vil ou abjeto, mas sim aquele que tem uma existência-clarão, ou seja, que é comum, que não é famoso, segundo a etimologia latina da palavra: in=elemento negativo, fama=célebre.

${ }^{3}$ A dissertação de mestrado, defendida em 1996 sob orientação da professora Céli Regina Jardim Pinto, foi publicada no ano de 2002.

${ }^{4}$ Os nomes de todas as pessoas diretamente envolvidas na história de Pierina inclusive o seu próprio, de familiares, amigos e testemunhas - foram trocados por

Anos 90, Porto Alegre, v. 13, n. 23/24, p.287-319, jan./dez. 2006 
pseudônimos, conforme exigência do Conselho de Ética na Pesquisa do Hospital Psiquiátrico São Pedro. Preservei, no entanto, os nomes originais de autoridades públicas, médicos, lugares, etc.

5 “Carta de Pierina à mãe”. HOSPÍCIO SÃO PEDRO. Prontuário n. 38120 - P. C. (APRS - Cx. 06).

6 “Carta ao Juiz de Garibaldi”. HOSPÍCIO SÃO PEDRO. Prontuário n. 38120 - P. C. (APRS - Cx. 06).

7 “Carta à Senhora infermeira (sic) Bernadeta da Santa Casa - Seção 15". HOSPÍCIO SÃO PEDRO. Prontuário n. 38120 - P. C. (APRS - Cx. 06).

8 “Carta aos dottores". HOSPÍCIO SÃO PEDRO. Prontuário n. 38120 - P. C. (APRS - Cx. 06).

${ }^{9}$ Ainda segundo Pelbart (1990, p. 135-6): “O que significa então para o pensar, poder pensar loucamente, poder enfim desarrazoar? (...) não basta gritar novas palavras de ordem em substituição às antigas - (...) Viva a Multiplicidade ou Viva a Diferença (...) - isso tudo não muda absolutamente nada, pois a desrazão não é uma nova ideologia, muito menos uma nova tecnologia - mas o exercício, no seio do próprio pensar e das práticas sociais, de uma nova forma de relacionar-se com o Acaso, com o Desconhecido, com a Força e com a Ruína. Trata-se enfim de um pensamento que não transforma a Força em acúmulo, mas em Diferença e intensidade. Isso tudo implica (...) inventar uma nova relação entre corpo e linguagem, entre a subjetividade e a exterioridade, entre os devires e o social (...)".

${ }^{10} \mathrm{Na}$ citação de fragmentos dos textos de Pierina, dos textos de médicos, representantes da polícia e do judiciário, ou ainda de depoimentos das testemunhas do processo mantiveram-se os termos originais, como 'doença', 'doença mental', 'alienação', 'louco' e 'loucura'.

${ }^{11}$ Sobre a história das mulheres e das relações de gênero, cf. SCOT'T, 1990; 1992 e DIAS, 1992; 1994.

${ }^{12}$ Cf. Cunha, 1986

${ }^{13}$ Estas assertivas também têm valor para pensar além das diferenças de gênero, ou seja, as de classe, raça/etnia, geração, etc., possibilitando a outros agrupamentos sociais colocarem-se com plenitude de direitos e reconhecimento de suas diferenças. ${ }^{14}$ Neste e no próximo parágrafo, estarei parafraseando Scott (1998) na reflexão que faz sobre como discutir experiência, aproximando a discussão de meu objeto.

${ }^{15}$ Segundo Latour (1994, p. 9), a rede é o que permite "reatar o nó górdio atravessando, tantas vezes quantas forem necessárias, o corte que separa os conhecimentos exatos e o exercício do poder, digamos a natureza e a cultura".

${ }^{16}$ É importante compreender também que a própria psiquiatria é um híbrido, como talvez todos os saberes modernos que, ao se constituírem, se representam como puros, separadores de natureza e cultura, mas que são efetivamente misturadores de tempos e espaços, são híbridos. Cf. Latour, 1994 e Foucault, 1989.

Anos 90, Porto Alegre, v. 13, n. 23/24, p.287-319, jan./dez. 2006 


\section{Yonissa Marmitt Wadi}

${ }^{17}$ Duplamente, enquanto edifício (artefato da técnica) ou instituição (lugar do saber-poder).

${ }^{18}$ Conforme Pelbart (1990, p. 132): "Por potencial de desterritorialização entendo aqui esse poder secreto e admirável de embaralhar os códigos, subverter as regras do jogo e transpor ou deslocar limites, sempre de outro modo, seja através de um devir-bicha, de um devir-negro, de um devir-nômade ou de um devir-louco, e ora assumindo um rosto estranho, ora ameaçador, sacrílego, herege, criminoso ou delirante".

${ }^{19}$ Importante deixar claro que estou pensando não na interpretação da loucura como doença mental, mas na provável desrazão que acometeu muitos daqueles homens e mulheres que um dia chegaram a ocupar os leitos dos manicômios e tornaram-se pacientes dos psiquiatras. Quando a desrazão não se travestiu de arte ou literatura, talvez não tenha existido nenhum outro espaço para ela, além da captura psiquiátrica (ou, antes do surgimento da ciência, o enclausuramento em prisões).

\section{Referências}

ALBERTI, Verena. Um drama em gente: trajetórias e projetos de Pessoa e seus heterônimos. In: SCHMIDT, Benito (org.). O biográfico: perspectivas interdisciplinares. Santa Cruz do Sul: EDUNISC, 2000. p.179-241.

CUNHA, Maria C. P. O espelho do mundo: Juquery, a história de um asilo. Rio de Janeiro: Paz e Terra, 1986. 144, 1989 .

Loucura, gênero feminino. Revista Brasileira de História, v.9, n.18, p.121-

DELEUZE, Gilles. Um retrato de Foucault. In: Conversações (1972 1990). São Paulo: Ed. 34, 1998a. p.127-147.

A vida como obra de arte. In: Conversações (1972 - 1990). São Paulo: Ed. 34, 1998b. p.118-126.

DIAS, Maria Odila L. S. Teoria e método dos estudos feministas: perspectiva histórica e hermenêutica do cotidiano. In: COSTA, Albertina O.; BRUSCHINI, Cristina (org.). Uma questão de gênero. Rio de Janeiro: Rosa dos Tempos; São Paulo: Fundação Carlos Chagas, 1992. p. 39-53. 
Novas subjetividades na pesquisa histórica feminista: uma hermenêutica das diferenças. Revista Estudos Feministas, Rio de Janeiro, $\mathrm{n}^{\circ}$ especial, p. 373-382, $2^{\circ}$ sem. 1994.

DUARTE, Luiz F. D. Investigação antropológica sobre doença, sofrimento e perturbação: uma introdução. In: DUARTE, Luiz Fernando D.; LEAL, Ondina F. (org.). Doença, sofrimento, perturbação: perspectivas etnográficas. Rio de Janeiro: Fiocruz, 1998. p. 9-27.

FARGE, Arlete. Marginais. In: BURGUIÈRE, André (org.). Dicionário das Ciências Históricas. Rio de Janeiro: Imago, 1993. p. 514-15.

FOUCAULT, Michel. A história da loucura na idade clássica. 2.ed. São Paulo: Perspectiva, 1989. 1990.

História da sexualidade II - O uso dos prazeres. 6.ed. Rio de Janeiro: Graal, A vida dos homens infames. In: . O que é um autor? Lisboa: Veja, 1992. p. 89-128.

GARCIA, Carla C. Ovelhas na névoa: um estudo sobre as mulheres e a loucura. Rio de Janeiro: Record/ Rosa dos Tempos, 1995.

GINZBURG, Carlo. O queijo e os vermes. O cotidiano e as idéias de um moleiro perseguido pela Inquisição. São Paulo: Companhia das Letras, 1987.

GOWING, Laura. Secret Births and Infanticide in Seventeenth-Century England. Past \& Present, Oxford, n. 156, p. 87 - 115, aug. 1997.

GREER, Germaine. Sexo e destino: a política da fertilidade bumana. Rio de Janeiro: Rocco, 1987.

HITA, Maria G. Gênero, ação e sistema: a reinvenção dos sujeitos. Lua Nova, São Paulo, n. 43, p. 109-130, 1998.

LANCETTI, Antonio. Loucura Metódica. Saúde e loucura, São Paulo, n.2, p.139$147,1990$.

LATOUR, Bruno. Jamais fomos modernos. Rio de Janeiro: Ed. 34, 1994.

PEDRO, Joana. Práticas que resistem através do tempo: aborto, infanticídio e abandono de crianças. Fronteiras - Revista Catarinense de História, Florianópolis, n.7, p. 04-28, 1999a.

PELBART, Peter P. Os loucos, trinta anos depois. Novos Estudos CEBRAP, São Paulo, n.42, p. 171-176, jul. 1995.

Anos 90, Porto Alegre, v. 13, n. 23/24, p.287-319, jan./dez. 2006 


\section{Yonissa Marmitt Wadi}

Manicômio mental: a outra face da clausura. Saúde e loucura, São Paulo, n. 2, p.131-138, 1990 .

ROLNIK, Suely. Psicologia: Subjetividade, Ética e Cultura. Saúde e Loucura, São Paulo, n. 6, p.13-21, 1997.

SCOTT, Joan. Gênero: uma categoria útil de análise histórica. Educação \& Realidade, Porto Alegre, v.15, n.2, p.5-22, jul/dez. 1990.

História das mulheres. In: BURKE, Peter (org.). A escrita da história: novas perspectivas. São Paulo: Editora da Universidade Estadual Paulista, 1992. p.63-95. 325, fev.1998.

A invisibilidade da experiência. Projeto História, São Paulo, n.16, p. $297-$

SHOWALTER, Elaine. The female maladie. Londres: Penguin Books, 1985.

VIANNA, Hermano. Robert Musil: as qualidades do homem moderno. In: VELHO, Gilberto (org.). Antropologia e literatura: a questão da modernidade. Rio de Janeiro: Programa de Pós-Graduação em Antropologia Social / Museu Nacional / UFRJ, 1988. p. 57-84 (Comunicação n. 12).

WADI, Yonissa M. Palácio para guardar doidos: uma história das lutas pela construção do hospital de alienados e da psiquiatria no Rio Grande do Sul. Porto Alegre: Ed. da Universidade / UFRGS, 2002a.

Louca pela vida: a história de Pierina. São Paulo: Pontifícia Universidade Católica de São Paulo, 2002b. (Tese de Doutorado em História). 